\title{
Analysis of Covid 19 Data in Indonesia Using Supervised Emerging Patterns
}

\author{
Untung Rahardja ${ }^{1}$, Ignatius Joko Dewanto ${ }^{2}$, Arko Djajadi ${ }^{3}$, Ariya Panndhitthana Candra ${ }^{4}$, \\ Marviola Hardini ${ }^{5}$ \\ ${ }^{1}$ Universiti Teknologi Malaysia \\ 2,3,4,5 University of Raharja \\ 'Sultan Ibrahim Chancellery Building, Jalan Iman, 81310 Skudai, Johor, Malaysia \\ 2,3,4,5Modern, Jl. Jenderal Sudirman No.40, RT.002/RW.006, Cikokol, Kec. Tangerang, Kota \\ Tangerang, Banten 15117 \\ e-mail: rahardjauntung@graduate.utm.my ${ }^{1}$, jokodewanto@gmail.com², \\ arkodjajadi@raharja.info ${ }^{3}$, ariya.pc@raharja.info ${ }^{4}$, marviola@raharja.info ${ }^{5}$
}

To cite this document :

Rahardja, U., Dewanto,J.I., Djajadi, A., Candra, P.A., \& Hardini, M. (2022). Analysis of Covid 19 Data in Indonesia Using Supervised Emerging Patterns. Aptisi Transactions on Management (ATM), 6(1), 91-101.

DOI :

https://doi.org/10.33050/atm.v6i1.1768

\section{Abstract}

This research method uses CRISP-DM with emerging pattern supervision modeling and EPM Algorithm. The contribution of the research is to assist the Government in overcoming the problem of the spread of the COVID-19 cluster in several regions in Indonesia. The research aims to implement information on the COVID-19 data mining pattern in the DKI Jakarta area. The problems faced are the difficulty of identifying the pattern of COVID-19 data in one area, it is difficult to dig up data on the http://corona.jakarta.go.id website. It is not easy to decide on the handling of COVID-19. The output of the research results in a cluster of information on COVID19 in the DKI Jakarta area based on Significance level depends on the Covid Map In terms of Region, Status, Gender, \& age And Signification can be the basis for determining covid OTG, DTG, and Positive. The theoretical and practical implications can be stated as follows: The use of supervised emerging pattern methods can affect the processing of COVID-19 data. For 5 Regions in DKI Jakarta and distribution to determine covid OTG, DTG, and Positive. The result of the development of this data mining system is to produce pattern reports to produce Supervised Emerging Patterns technology for decision making at the COVID-19 Task Force in DKI Jakarta.

Keywords: CRISP-DM, Emerging Pattern Mining Algorithm, COVID-19, Indonesia

\section{Introduction}

Indonesia is the fastest country in the development of COVID-19 can be seen on a google search: Indonesia COVID-19, based on daily statistical changes from the https://covid19.go.id website [1].

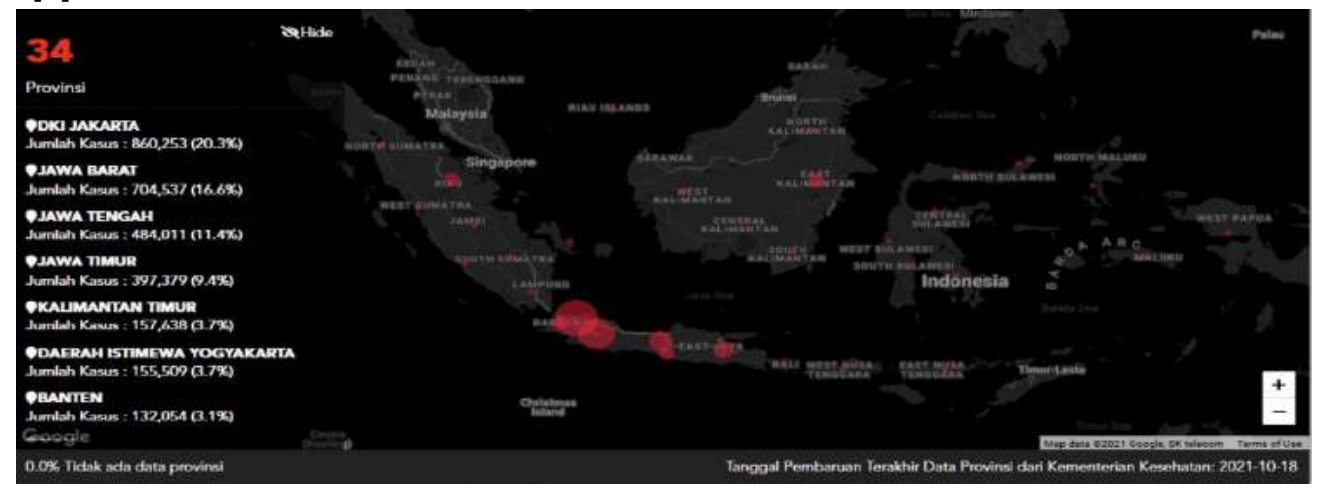

Figure 1. Indonesia Grow Covid 19 Statistics 
Where the data has increased significantly, as of October 19, 2020, there were 4,235,384 confirmed cases of covid 19 that occurred in Indonesia, which are data: active cases, recovered cases, and cases of death, and at this time, Indonesia has ranked 3rd in Asia Ranked, and 16th at the world level [2].

This study tries to manage covid 19 data located in DKI Jakarta on the https://corona.jakarta.go.id site, mapping data consisting of the municipality, status, gender, age, lab results, status: independent isolation or being treated [3]. Based on the existing data, the researcher will find out which data are interesting to produce patterns to facilitate decision making and report generation. The resulting pattern is selected by determining to learn, and two attributes are selected as an item set. This application is implemented with a Data Mining application using the Supervised Emerging Patterns method to manage large data, which is expected to help facilitate decision-making. Based on the existing data, knowledge about the patterns that exist in the COVID-19 data will be obtained.

\section{Research Method}

The flow in this research is adjusted to the step approach in the CRISP-DM method to introduce the covid 19 pattern. The understanding of the stages refers to the research, but there are differences in the object of the research to be carried out. It has three stages of research: 1) data collection by conducting interviews and questionnaires. The data collected is related to covid 19 information at https://corona.jakarta.go.id [4]. The data source is obtained from the corona Jakarta information system https://corona.jakarta.go.id, 2) is the business and data understanding stage. The processes at this stage are business understanding, data understanding, and data preparation process, 3 ) It is a modeling and evaluation stage. The process at this stage is also part of the CRISP-DM methodology. The operations at this stage, namely, the modeling process, the evaluation process, and the deployment process. The system development method used in this research is the Cross-Industry Standard Process for Data Mining (CRISP-DM), which consists of six phases as follows:[5]

\subsection{The phase of business understanding (Business Understanding Phase)}

1. Determination of project objectives and requirements in detail within the scope of business or research. The research aims to develop a supervised emerging pattern technology for decision making that is applied to the covid data. Presented at https://corona.jakarta.go.id to help make it easier for the covid prevention agency and related agencies to manage patterns from the selected learning and itemset so that a decision and knowledge can be obtained about the patterns in the COVID-19 data in the DKI Jakarta area.

2. It is translating the purpose of the data mining problem formula limitation. This study only focuses on developing supervised emerging pattern applications that only use 2 (two) items: http://corona.jakarta.go.id and http://data.jakarta.go.id municipal attributes, status, gender, age, results in the lab, status, which is used as an itemset against selected learning.

3. Prepare initial strategies to achieve goals The initial strategy in this research is to collect related data from various sources, which will later be run in the PHP programming language.

\subsection{Business Understanding Phase}

The use of the resulting data is secondary data that is internal from two different data sources. For corona data, it consists of municipal data, status, gender, age, lab results, status: self-isolation or treatment, which was obtained from http://corona.jakarta.go.id in Xls format with the number of records: 1184 records, while for regional data obtained from http://data.jakarta.go.id in excel form with the number of records: 5 records. The two data will be carried out in a data integration process to make it easier to manage. The data analysis was carried out to know user needs' expectations in overcoming the coronavirus's handling. It evaluates the quality of the data by carrying out the data cleansing process or removing noise data that is considered invalid. Next, collect data on isolation, status, lab results, and PRR tests. 


\subsection{Preparation Data Phase}

Prepare initial data and collect data that will be used for the entire next phase. This phase is the selection of data. The data selected are the two data that have been obtained as comparison material. : 1) the design of the data set and the attributes that will be selected from the http://corona.jakarta.go.id data is the serial number, lab results that identify positive and negative and status: self-isolated and treated. http://jakarta.go.id has validated the selection of the attribute by conducting a questionnaire and asking whether the attribute can help determine the distribution of covid 19 in the Jakarta DIK area. Selection of cases and variables to be analyzed and the appropriate analysis to be carried out for analysis and the appropriate ones include municipality, sub-district, ward, laboratory results, patient number, status, gender, and age, while variable changes are made based on municipality, status, lab results, gender, and age, as initial data preparation to proceed to model tools.

\subsection{Modeling Data Phase}

Data mining techniques (modeling) using the method algorithm. Emerging pattern mining, calibrated model rules to optimize results, specifying several techniques used for the same data mining problem, the process can return to the data processing phase into a form that matches the specifications of the needs of certain data mining techniques. Modeling is done by using learning by specifying two attributes as the itemset. Based on the results of growth-rated confidence, it will be assessed whether the pattern is attractive or not to be used as decisionmaking based on the percentage generated in the resulting confidence calculation.

\subsection{Evaluation Phase}

The evaluation phase is carried out by asking the questionnaire form whether the attributes that have been selected match or not with the corona data available at http://jakarta.co.id. The questionnaire results said it could represent the attributes, namely: region, positive and negative status, gender, and age.

\subsection{Deployment}

At this stage, the system is implemented by translating patterns (patterns) to the results obtained from the evaluation in the previous stage or the data mining process, which is carried out using a model created using emerging patterns. Using rapid miner and PHP applications to implement pattern report results. The results of the development of this data mining system produce pattern reports, resulting in Supervised Emerging Patterns technology for decisionmaking on data on corona developments in Indonesia. More complex development: It is hoped that the covid task force can apply the Supervised Emerging Patterns data mining system for decision-making on covid data in Indonesia 


\section{Analysis and Discussion}

At this stage of the business process that occurs is referring to the data - data that has been taken from COVID - 19 Jakarta while the data of the business process are:

\begin{tabular}{|c|c|c|c|c|}
\hline Tanggal & $\begin{array}{c}\text { Jumlah } \\
\text { Orang di } \\
\text { Test }\end{array}$ & $\begin{array}{l}\text { Orang } \\
\text { Positif } \\
\text { Harian }\end{array}$ & Positif & $\begin{array}{c}\text { Positivity Rate } \\
\text { Spesimen } \\
\text { Harian }\end{array}$ \\
\hline $29-02-2020$ & 40 & 0 & 0 & $0,0 \%$ \\
\hline $01-03-2020$ & 39 & 0 & 0 & $0,0 \%$ \\
\hline $02-03-2020$ & 3 & 0 & 0 & $0,0 \%$ \\
\hline $03-03-2020$ & 15 & 3 & 3 & $20,0 \%$ \\
\hline $04-03-2020$ & 7 & 0 & 0 & $0,0 \%$ \\
\hline $05-03-2020$ & 27 & 0 & 3 & $11,1 \%$ \\
\hline $06-03-2020$ & 5 & 0 & 0 & $0,0 \%$ \\
\hline $07-03-2020$ & 26 & 0 & 0 & $0,0 \%$ \\
\hline $08-03-2020$ & 56 & 1 & 0 & $0,0 \%$ \\
\hline $09-03-2020$ & 73 & 27 & 25 & $34,2 \%$ \\
\hline $10-03-2020$ & 52 & 2 & 0 & $0,0 \%$ \\
\hline $11-03-2020$ & 48 & 26 & 3 & $6,3 \%$ \\
\hline $12-03-2020$ & 56 & 10 & 23 & $41,1 \%$ \\
\hline $13-03-2020$ & 30 & 7 & 10 & $33,3 \%$ \\
\hline $14-03-2020$ & 44 & 16 & 3 & $6,8 \%$ \\
\hline $15-03-2020$ & 41 & 2 & 15 & $36,6 \%$ \\
\hline $16-03-2020$ & 47 & 25 & 2 & $4,3 \%$ \\
\hline $17-03-2020$ & 104 & 38 & 26 & $25,0 \%$ \\
\hline $18-03-2020$ & 132 & 51 & 38 & $28,8 \%$ \\
\hline $19-03-2020$ & 154 & 13 & 48 & $31,2 \%$ \\
\hline $20-03-2020$ & 118 & 44 & 12 & $10,2 \%$ \\
\hline $21-03-2020$ & 501 & 39 & 437 & $9,6 \%$ \\
\hline $22-03-2020$ & 1097 & 49 & 430 & $3,4 \%$ \\
\hline $23-03-2020$ & 378 & 71 & 471 & $7,7 \%$ \\
\hline $24-03-2020$ & 347 & 45 & 446 & $20,5 \%$ \\
\hline $25-03-2020$ & 196 & 43 & 437 & $23,5 \%$ \\
\hline $26-03-2020$ & 248 & 51 & 448 & $14,9 \%$ \\
\hline $27-03-2020$ & 199 & 37 & 435 & $24,0 \%$ \\
\hline $28-03-2020$ & 359 & 98 & 502 & $9,7 \%$ \\
\hline $29-03-2020$ & 127 & 26 & 426 & $80,3 \%$ \\
\hline
\end{tabular}

Figure 2 Disting - Status Positive

Figure 1. Above shows an example of a data fragment. In these Excel Sheets there are 1053 rows of data records consisting of 3 columns consisting of the following columns: Municipality/Regency, Status, Gender, \& Age.

The following is a picture of the Entry Relation diagram that was formed based on the analysis of the 4 excel sheets above:



Figure 3. Class Diagram SATGAS COVID-19 Part 1 
The following is an Activity Diagram that is formed based on the analysis of the 4 Excel Sheets above:

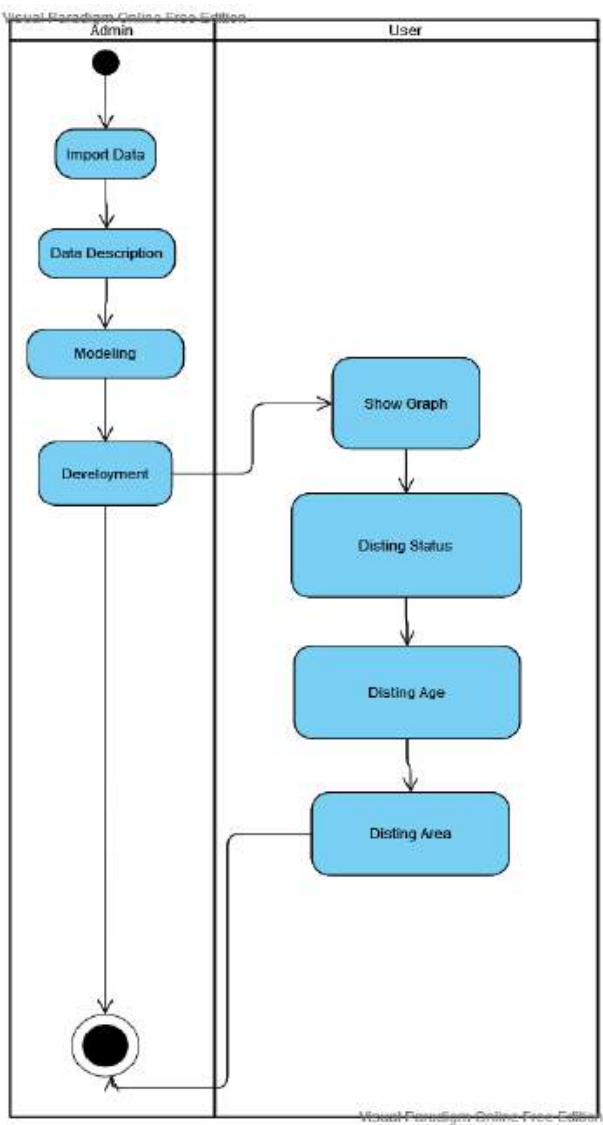

Figure 4. Class Diagram SATGAS COVID-19 Part 2

The following is a picture of the structure of the COVID-19 Task Force database table.

Table I. Gender Table

\begin{tabular}{|l|l|l|}
\hline Column name & Data Type & Value \\
\hline Id_gender & Int & 4 \\
\hline gender & Enum & Man \& Women \\
\hline
\end{tabular}

Table II. Status Table

\begin{tabular}{|l|l|l|}
\hline Column Name & Data Type & Value \\
\hline Id_status & Int & 4 \\
\hline Status & Varchar & 20 \\
\hline
\end{tabular}

Table III. Age Table

\begin{tabular}{|l|l|l|}
\hline Column Name & Data Type & Value \\
\hline Id_age & Int & 4 \\
\hline Category_us & Varchar & 20 \\
\hline
\end{tabular}


Table IV. Area Table

\begin{tabular}{|l|l|l|}
\hline Column Name & Data Type & Value \\
\hline Id_area & Int & 4 \\
\hline Area & Varchar & 20 \\
\hline
\end{tabular}

Table V. Daily Transaction Table

\begin{tabular}{|l|l|l|}
\hline Column Name & Data Type & Value \\
\hline Id_daily & Int & 4 \\
\hline Id_gender & Int & 4 \\
\hline Id_status & Int & 4 \\
\hline Id_age & Int & 4 \\
\hline Id_area & Int & 4 \\
\hline age & Int & 4 \\
\hline
\end{tabular}

\subsection{Data Understanding}

In the study [6] entitled "Business and Data Understanding in the context of establishing an Emerging Partner Implementation on Covid-19 data in DKI Jakarta", it was explained that the stage of data understanding begins with collecting initial data and the results of activities to familiarize themselves with the data to identify data problems. To determine first insights into the data or detect subsets of interest to form hypotheses for hidden information.

Collecting the Initial Data, the initial data collection is done by literature study \& observation. Observations are used to obtain initial data that supports research related to the portion pattern of the spread of the COVID-19 virus in DKI Jakarta [7], which was taken on the http://corona.jakarta.go.id website page.

Table VI. Stage Of Detailing Data

\begin{tabular}{|c|c|}
\hline Data Understan & \\
\hline Function Name & Data Description \\
\hline Input & Lab Result, Status, Gender, Age \\
\hline Output & MS. Excel \\
\hline Purposes & $\begin{array}{l}\text { perform analysis and understand the data } \\
\text { obtained from the results of initial data collection }\end{array}$ \\
\hline
\end{tabular}

Table VII. Explore the Data 


\begin{tabular}{|l|l|}
\hline \multicolumn{2}{|l|}{ Data Understanding } \\
\hline Function Name & Explore the Data \\
\hline Input & MS.Excel EPM \\
\hline Output & Result Age, Status, Gander, Age \\
\hline Purposes & $\begin{array}{l}\text { Conduct data exploration and structural analysis } \\
\text { the table on Ms. Excel EPM }\end{array}$ \\
\hline
\end{tabular}

Table VIII. Data Understanding

\begin{tabular}{|c|c|}
\hline \multicolumn{2}{|c|}{ Data Understanding } \\
\hline Function Name & Verify Data Quality \\
\hline Input & Table Result Lab, Table Status, Gender Table, Age Table \\
\hline Output & $\begin{array}{l}\text { Lab Results Table, Status Table, Gender Table, Age Table } \\
\text { (Verification) }\end{array}$ \\
\hline Purposes & $\begin{array}{l}\text { Carry out the data verification process. Data verification is carried } \\
\text { out on the table structure, the data contained in the table and the } \\
\text { integration between tables. }\end{array}$ \\
\hline
\end{tabular}

\subsection{Data Preparation}

In a study [8] entitled "Business and Data Understanding in the context of forming a traditional market layout and layout model in increasing sales profits using the association rule and decision tree method (a case study in the city of Bandung)", it is explained that the data preparation stage includes all activities that build a dataset. Final data (data to be entered into the modeling) of the initial raw data. Data preparation consists of all activities to build a database that will be entered into the modeling tool from the initial raw data or create a new database for data mining setup. Data preparation includes all activities to build data sets that will be processed in the modeling process using the Jumping Emerging Pattern (JEP) algorithm to extract information [9].

\subsection{Research Implementation}

after determining the problem and how to solve it, you can write down the results of your implementation, which is explained theoretically descriptions, both qualitatively and quantitatively which can be in the form of graphics, images, diagrams, and others that make the reader easy to understand

\section{Data Set Description}

Table IX. Data Preparation Part 1

\begin{tabular}{|l|l|}
\hline \multicolumn{2}{|l|}{ Data Preparation } \\
\hline Function Name & Data Set Description \\
\hline Input & Lab Results Table, Status Table, Gender Table, Age Table (Verification) \\
\hline Output & $\begin{array}{l}\text { Table Gender, Table Age Category, Table status } \\
\text { Table Daily, Table Age, Table Result Lab }\end{array}$ \\
\hline Purposes & $\begin{array}{l}\text { Designing data sets in accordance with the Purposes of data mining. At this } \\
\text { stage, the related tables are selected to simplify the data selection process. }\end{array}$ \\
\hline
\end{tabular}




\section{Select Data}

Table X. Data Preparation Part 2

\begin{tabular}{|c|c|}
\hline Data Preparatio & \\
\hline Function Name & Data (Select Data) \\
\hline Input & $\begin{array}{l}\text { Table Gender, Table Age Category, Table status } \\
\text { Table Daily, Table Age, Table Result Lab }\end{array}$ \\
\hline Output & Table Daily \\
\hline Purposes & $\begin{array}{l}\text { The selected table corresponds to } \\
\text { the introduction of the pattern of the spread of covid } 19 \text { is a } \\
\text { combination of the Gender table, age_category table, status table, } \\
\text { region table, lab results table }\end{array}$ \\
\hline
\end{tabular}

\section{Construct Data}

Table XI. Data Preparation Part 3

\begin{tabular}{|c|c|}
\hline \multicolumn{2}{|l|}{ Data Preparation } \\
\hline Function Name & Construct Data \\
\hline Input & Table daily \\
\hline Output & Table daily \\
\hline Initial Table Structure & id_gender, id_status, id_age id_area, age \\
\hline Final Table Structure & id_daily, id_gender, id_status, id_age id_area, age \\
\hline Purposes & $\begin{array}{l}\text { Carry out the data development process (table). Data } \\
\text { development can be done by adding queries. }\end{array}$ \\
\hline
\end{tabular}

\section{Integrate Data}

Merge two or more tables that have different information about the same object into a new data set that has been prepared in the early stages of data preparation. The integrated table is the result of data transformation in the previous stage.

\section{Clean Data}

Table XII. Data Preparation Part 4

\begin{tabular}{|l|l|}
\hline \multicolumn{2}{|l|}{ Data Preparation } \\
\hline Function Name & Construct Data \\
\hline Input & Table daily \\
\hline Output & Table daily \\
\hline Initial Table Structure & id_gender, id_status, id_age id_area, age \\
\hline Final Table Structure & id_daily, id_gender, id_status, id_age id_area, age \\
\hline Purposes & $\begin{array}{l}\text { Carry out the data development process (table). Data development } \\
\text { can be done by adding queries. }\end{array}$ \\
\hline
\end{tabular}




\subsection{Modeling}

The data mining technique and algorithm that will be applied in this research is the Emerging Patterns data mining method to determine interesting patterns from mining business permit data in Indonesia [10]. The Emerging Patterns technique was chosen based on previous research discussed [11] in one of the studies researched "Mining Frequent Pattern with Attribute Oriented Induction High-Level Emerging Pattern (AOI-HEP)." Based on this research, the usefulness of Emerging Patterns is explained, namely the use of High-Level Emerging Patterns (HEP), which helps determine patterns that often appear. The pattern results will be influenced by the learning attributes they choose, [1] researched "A Novel Fibonacci Windows Model for Finding Emerging Patterns Over Online Data Stream," saying that the use of Emerging Patterns to emerge patterns from data streaming is so extensive. Based on several previous studies, researchers are interested in researching COVID-19 data development using emerging patterns techniques. Following the objectives to be achieved, this research will build a supervised emerging patterns data mining application applied to COVID-19 data development data [12]. PHP-based applications and supervised methods are expected to help display interesting patterns from Covid-19 data development data [13]. Modeling is done by using learning by specifying two attributes as the itemset. Based on the growth rate and confidence results, it will be assessed whether the pattern is attractive or not to be used as a decision based on the percentage generated in calculating the resulting confidence. Selection of data mining techniques, algorithms, and determining parameters with optimal values. At the modeling stage, there are several things to do, among others, choosing a modeling technique, building a model, and assessing the model:

1. They were choosing a Modeling Technique (Select Modeling Technique). The data mining technique chosen is confidence using the Emerging Partners Supervised and Emerging Partners Mining algorithms, which are very appropriate to achieve the initial goal of this study, namely exploring knowledge about student predictions taking courses [14]. Data mining modeling begins with making calculations to find the confidence value.

2. Following the general provisions that have been applied, the status criterion is one of the benchmarks for people to be positive for coronavirus in an area in DKI Jakarta [15].

3. Assessing Model (Assess Model) Modeling is done by forming data patterns using the Emerging Partners Supervised algorithm [16]. The next step is to find the jumping Emerging Partners (JEP) value with a predetermined confidence value. To select an attribute using a formula:

a. Choosing a Modeling Technique (Select Modeling Technique) The data mining technique chosen is confidence using the Emerging Partners Supervised and Emerging Partners Mining algorithms, which are very appropriate to achieve the initial goal of this study, namely exploring knowledge about student predictions taking courses. Data mining modeling begins with making calculations to find the confidence value [17].

b. Building a Model Following the general provisions that have been applied, the status criterion is one of the benchmarks for people to be positive for coronavirus in an area in DKI Jakarta.

c. Assessing Model (Assess Model) Modeling is done by forming data patterns using the Emerging Partners Supervised algorithm. The next step is to find the jumping Emerging Partners (JEP) value with a predetermined confidence value [18]. To select an attribute using a formula:

\section{JEP Formula}

$$
\begin{aligned}
& X=\{(\text { Scatter }- \text { positive })\} \\
& \text { Sup D1 }(x)=\frac{\text { count } D 1(x)}{|\mathrm{D} 1|}=\underline{2053}=0.940019 \\
& X=\{(\text { Scatter }- \text { negative })\} \\
& \text { Sup D2 }(x)=\frac{\text { count D2 }(x)}{|\mathrm{D} 2|}=\frac{224}{2184}=0.10256 \\
& \text { Grow Rate }=\frac{\text { Sup D2 }(x)}{\operatorname{Sup~D1}(x)}=0.10256=0.109108 \\
& 0.940019
\end{aligned}
$$




\subsection{Evaluation}

The evaluation in this study is more focused on the model or pattern generated by the Emerging Partners Mining algorithm. The resulting model is analyzed to determine whether the consequent way follows the standards on the http://corona.jakarta.go.id website. If the resulting pattern is not appropriate, then further analysis of the resulting design needs to be carried out to produce recommendations for improvement in the atmosphere of the status of people affected by covid, which is expected to help map the spread of covid-19 in DKI Jakarta. (Region, Status, Gender \& Age) for determining the pattern you want to generate [19].

\subsection{Deployment}

Based on the book of algorithms and data mining, the deployment stage is reporting. And the deployment stage can also be defined as applying data mining processes in parallel to other regions, statuses, genders, and ages [20]. In this case, the stages of spreading data mining can be carried out in all existing areas. on the http://corona.jakarta.go.id website. In this research, the deployment stage uses an emerging pattern approach by using a PHP programming application to implement the results of the pattern reports [11]. The result of the development of this data mining system is to produce pattern reports to produce Supervised Emerging Patterns technology for decision making at the Covi-19 Task Force in DKI Jakarta [21].

\section{Conclusion}

Signification level depends on the Covid Map In terms of Region, Status, Gender, \& age. And Signification can be the basis for determining covid OTG, DTG, and Positive. Based on the research results, the theoretical and practical implications can be stated as follows Theoretical Implications: The use of supervised emerging pattern methods can affect the processing of COVID-19 data. For 5 Regions in DKI JAKARTA and DISTING distribution to determine covid OTG, DTG, and Positive.

Practical Implications: With this system, the Task Force Team can make policies and prevention. 1. Covid 19 data identified by data patterns in 1 DKI Jakarta area, in the form of daily transactions related to the area, positive status and waiting for results, male and female gender, age categories: 1) 5 years and under, 2) 6 -19 years, 3) 20-29 years, 4) $30-39$ years, 5) $40-49$ years, 6) 50-59 years, 7) 60 years and over. 2. Exploring data mining is carried out by the following steps: 1) Understanding the data by collecting the initial data, including a) describing the data, b) exploring the data, c) verifying the quality of the data; 2) Data processing (data preparation): a) describing data (data set description), b) selecting data (select data), c) building data (construct data), d) integrating data (integrating data), e) cleaning data (clean data); 3) Modeling: a) choosing a data modeling technique (select modeling technique), b) building a model, assessing the model (assess model); 4) Evaluation (evaluation); 5) Development (deployment). 3. Developing this data mining system is to generate pattern reports and produce Supervised Emerging Patterns technology for decision making at the Covi-19 Task Force in DKI Jakarta.

\section{Acknowledgment}

The author would like to thank the the University of Raharja for their financial support and for providing a place to support this research through research system analysis.

\section{References}

[1] I. J. Dewanto and A. P. Candra, "IMPLEMENTASI EMERGING PATERN UNTUK DATA COVID 19 PADA DKI JAKARTA," JI-Tech, vol. 17, no. 1, pp. 33-40, 2021.

[2] P. Skendros et al., "Complement and tissue factor-enriched neutrophil extracellular traps are key drivers in COVID-19 immunothrombosis," J. Clin. Invest., vol. 130, no. 11, pp. 6151-6157, 2020.

[3] F. W. Wibowo, "Prediction of air quality in Jakarta during the COVID-19 outbreak using long short-term memory machine learning," in IOP Conference Series: Earth and Environmental Science, 2021, vol. 704, no. 1, p. 12046.

[4] A. Rohman, "DASAR PEMBENTUKAN PERATURAN DAERAH DAN PERAN KEPALA DAERAH TERHADAP UPAYA PENCEGAHAN PENYEBARAN COVID-19," ADIL J. Huk., vol. 11, no. 2, 2020. 
[5] U. Rahardja, A. N. Hidayanto, P. O. H. Putra, and M. Hardini, "Immutable Ubiquitous Digital Certificate Authentication Using Blockchain Protocol," J. Appl. Res. Technol., vol. 19, no. 4, pp. 308-321, 2021.

[6] I. Sutedja, P. Yudha, N. Khotimah, and C. Vasthi, "Building a Data Warehouse to Support Active Student Management: Analysis and Design," in 2018 International Conference on Information Management and Technology (ICIMTech), 2018, pp. 460-465.

[7] F. E. S. Silalahi, F. Hidayat, R. S. Dewi, N. Purwono, and N. Oktaviani, "GIS-based approaches on the accessibility of referral hospital using network analysis and the spatial distribution model of the spreading case of COVID-19 in Jakarta, Indonesia," BMC Health Serv. Res., vol. 20, no. 1, pp. 1-20, 2020.

[8] T. M. Al Taleb, S. Hasan, and Y. Y. Mahdi, "Enhance the Performance of a Data Warehouse by Indexed View," J. Fundam. Appl. Sci., vol. 10, no. 6S, pp. 211-215, 2018.

[9] N. A. Sakr, M. Abu-ElKheir, A. Atwan, and H. H. Soliman, "A multilabel classification approach for complex human activities using a combination of emerging patterns and fuzzy sets," Int. J. Electr. Comput. Eng., vol. 9, no. 4, p. 2993, 2019.

[10] G. Shmueli, P. C. Bruce, P. Gedeck, and N. R. Patel, Data mining for business analytics: concepts, techniques and applications in Python. John Wiley \& Sons, 2019.

[11] H. L. H. S. Warnars, N. Anwar, R. Randriatoamanana, and H. E. P. Sanchez, "Mining Similar Pattern with Attribute Oriented Induction High level Emerging Pattern (AOI-HEP) data mining technique," J. Teknol., vol. 79, no. 7-2, 2017.

[12] V. F. Brock and H. U. Khan, "Are enterprises ready for big data analytics? A survey-based approach," Int. J. Bus. Inf. Syst., vol. 25, no. 2, pp. 256-277, 2017.

[13] M. M. Khan, M. R. Amin, A. Al Mamun, and A. A. Sajib, "Development of Web Based Online Medicine Delivery System for COVID-19 Pandemic," J. Softw. Eng. Appl., vol. 14, no. 1 , pp. 26-43, 2021.

[14] M. Tsiakmaki, G. Kostopoulos, S. Kotsiantis, and O. Ragos, "Implementing AutoML in educational data mining for prediction tasks," Appl. Sci., vol. 10, no. 1, p. 90, 2020.

[15] A. Padmo and I. E. Joesoef, "COVID-19 as Force Majeure in Insurance Agreement," Mulawarman Law Rev., pp. 114-125, 2020.

[16] N. Boodhun and M. Jayabalan, "Risk prediction in life insurance industry using supervised learning algorithms," Complex Intell. Syst., vol. 4, no. 2, pp. 145-154, 2018.

[17] N. Anwar, H. L. H. S. Warnars, and H. E. P. Sanchez, "Survey of emerging patterns," in 2017 IEEE International Conference on Cybernetics and Computational Intelligence (CyberneticsCom), 2017, pp. 11-18.

[18] G. Poezevara et al., "A computational selection of metabolite biomarkers using emerging pattern mining: a case study in human hepatocellular carcinoma," J. Proteome Res., vol. 16, no. 6, pp. 2240-2249, 2017.

[19] A. Kramer and K. Z. Kramer, "The potential impact of the Covid-19 pandemic on occupational status, work from home, and occupational mobility." Elsevier, 2020.

[20] E. Fernandes, M. Holanda, M. Victorino, V. Borges, R. Carvalho, and G. Van Erven, "Educational data mining: Predictive analysis of academic performance of public school students in the capital of Brazil," J. Bus. Res., vol. 94, pp. 335-343, 2019.

[21] M. Chisholm, Modern world development: a geographical perspective. Routledge, 2020. 